Kafkas Üniversitesi Sosyal Bilimler Enstitüsü Dergisi

Kafkas University Journal of the Institute of Social Sciences

Bahar Spring 2021, Sayı Number 27, 145-157

DOI:10.9775/kausbed.2021.009

Gönderim Tarihi: 17.03.2021

Kabul Tarihi: 17.05.2021

İLYAS KÖYÜNDEN (DIYYARBAKIR-ÇÜNGÜŞ) DERLEME SÖZLÜĞÜNE KATKILAR

\title{
Contributions to the Compilation Dictionary from the İlyas Village (Diyarbakır-Çüngüş)
}

\author{
Mehmet Emin TUĞLUK \\ Dr. Öğr. Üyesi., Batman Üniversitesi, \\ Fen-Edebiyat Fakültesi, Türk Dili ve Edebiyatı Bölümü, \\ Yeni Türk Dili Ana Bilim Dalı \\ emintugluk@gmail.com \\ ORCID ID: 0000-0003-1866-5580 \\ Çalışmanın Türü: Araştırma
}

$\ddot{O} z$

Bir dilin söz varlı̆ğ sözlü ve yazılı olarak sonraki nesillere aktarılmaktadır. Günümüzde iletişim teknolojisinin gelişmesiyle sözlü kültürde varlığını sürdüren halk hikâyeleri, masal destan vb. anlatı türlerinin yerini teknolojik aletler almaya başlamıştır. Bu durum gerek bu sözlü anlatı türlerinde yaşayan gerekse ağızlarda günlük hayatta kullanılan söz varlı̆ıının unutulmasını hızlandırmıştır. Türkiye'de söz varlı̆ı̆ın unutulmadan yazıya aktarılması amacıyla 1932 yılından itibaren derleme çalışmaları yapılmaya başlanmıştır. Bu derleme çalışmalarının son şeklini Türkiye'de Halk Ağzından Derleme Sözlüğ̈̈ oluşturmaktadır. Ancak ağızlarda kullanıldı̆̆ı halde hâlâ Derleme Sözlüğ̈̈nde yer almayan söz varlı̆̆ına rastlanmaktadır. Derleme Sözlüğünde yer almayan ancak ă̆ızlarda yaşayan söz varlığının unutulmadan yazıya aktarılması bu açıdan önemlidir. Bu çalışmada Diyarbakır'ın Çüngüş̧ ilçesine bağhl Illyas köyünden (Malkaya) söz varlı̆̆ı derlenmiștir. Derlenen bu söz varlı̆̆ıyla Derleme Sözlüğünün ileride yapılacak güncel baskılarına katkı sunulması amaçlanmıștır.

Anahtar Kelimeler: Diyarbakır Ă̆zı, Çüngüşs Ă̆zı, Ilyas (Malkaya) köyü, Derleme Sözlüğüne Katkı, Ă̆gz Araştırmaları.

Abstract

Vocabulary of a language is transferred to the next generations either verbally or in writing. Today, with the development of communication techology, folk tales, fairy, tales, epics, etc. narrative genres began to be replaced by technological tools. This situation has accelerated the forgetting of the vocabulary used in daily life and living in verbal narrative genres. In Turkey, compilation studies have been started since 1932 in order to transfer the vocabulary to the writing without being forgotten. The final form of these compilation studies is the Halk A ̆gzından Derleme Sözlüğ̈̈ (Dictionary of Compilation from People's Dialect) in Turkey. However, although it is used in the dialects, there is still a vocabulary that is not included in the Compilation Dictionary. In this respect, it is important to write down the vocabulary that is not included in the the Compilation Dictionary, but lives in the dialects, without being forgotten. In this study, vocabulary from Illyas village (Malkaya) of Çüngüss district of Diyarbakır was compiled. With this compiled vocabulary, it is aimed to contribute to the up-to-date editions of the Compilation Dictionary.

Keywords: Diyarbakır Dialect, Cüngüș Dialect, Illyas (Malkaya) Village, Contribution to the Compilation Dictionary, Dialect Research. 


\section{GİRIŞ}

Türkiye'de halk ağzından söz varlığının derlenmesi 1932 yılında Türk Dil Kurumunun, o günkü adıyla Türk Dili Tetkik Cemiyetinin öncülüğünde başlamıştır. 1932 yılında bu amaçla bir "Söz Derleme Talimatnamesi" hazırlanmıştır. Türkiye'de halk ağzından söz derleme işi iki defa yapılmıştır. Birinci derleme 1932-1934, ikinci derleme 1952-1959 yılları arasında yapılmıştır. İlk derlemede 153.500, ikinci derlemede ise 450.000 fiş derlenmiştir. Günümüzde Türk Dil Kurumu tarafından basılan Türkiye'de Halk Ağzindan Derleme Sözlüğü bu ikinci derlemeye dayanmaktadır (DS, 2009: V-X).

Leyla Karahan, Anadolu A ğılarının Sinıflandirılması adlı eserinde Diyarbakır'ı Doğu Grubu Ağızları içerisinde ele almaktadır. Karahan, Doğu Grubu Ağızlarını dört alt gruba ayırmakta, Diyarbakır'1 ise bu alt gruplar içerisinde 1. gruba almaktadır. Karahan, Diyarbakır ağzının da yer aldığı Doğu grubuna ait 1. alt grubun özelliklerini şu şekilde belirtir (Karahan, 2011: 69-70):

a. Ünlü kalınlaşmaları, kalınlık-incelik uyumsuzluğuna sebep olur.

b. g / $\breve{g}$ ünsüzü, iki ünlü arasında ve hece sonunda korunur (baġladı, ağır).

c. “k/k” ünsüzü ön seste korunur (kapi).

ç. Arapça ve Farsçanın ünlü ve ünsüzler üzerinde etkisi hissedilir ('ayni, var, kapi).

d. Zamir kökenli teklik 1. ve 2. şahıs ekleri ile bildirme ekleri geniş ünlülüdür (gelirem, gelmişsen).

e. Duyulan geçmiş zaman eki (Urfa hariç) tek şekillidir (görmiş).

Diyarbakır ili ağzı ile ilgili bugüne kadar sınırlı sayıda çalışma yapılmıştır (Beysanoğlu, 1966; Boz, 1996; Eker, 2008; Ölmez, 2010; Erten, 2011; Özçelik ve Boz, 2011; Başkan, 2012; Nakiboğlu, 2015; Sökmen, 2016; Erten ve Başkan, 2016; Başkan ve Özkan, 2017; Sökmen, 2017; Baran, 2019; Baran ve Erten, 2020). İlyas köyünün bağlı olduğu Çüngüş ağzı Sadettin Özçelik ve Erdoğan Boz tarafindan Diyarbakır Illi Çüngüş ve Çermik Yöresi Ă̆zı (Dil İncelemesi-Metinler-Sözlük) adıyla yayımlanmıştır (Özçelik ve Boz, 2011). Bu eserde Malkaya köyünden de çeşitli gelenek, görenek, hatıra ve mutfak eşyalarının yer aldığı iki metin derlenmiştir (Özçelik ve Boz, 2011). Ayrıca Erdoğan Boz, Çüngüss ve Çermik Yöresi A ğzından Derleme Sözlügüüne Katkılar adlı yazısıyla Çüngüş yöresinden söz varlığ 1 derlemiştir (Boz, 1996: 112-113).

Diyarbakır'ın Çüngüş ilçesine bağlı İlyas (Malkaya) köyü Türkiye 
Türkçesi Ağızları için zengin bir söz varlığına sahiptir. Köydeki söz varlığının bir kısmının bugüne kadar Derleme Sözlüğü (DS) ve diğer Anadolu ağızlarının söz varlığında yer almadığı tespit edilmiştir. $\mathrm{Bu}$ çalışmada DS'ye katkı sunmak amacıyla Diyarbakır ili Çüngüş ilçesine bağlı İlyas (Malkaya) köyünden söz varlığı derlenmiştir.

Derlenen bu söz varlı̆g “ “İyas Köyünde Kullanılıp Türkiye'de Halk Ağzından Derleme Sözlüğünde Bulunmayan Söz Varlığı” ile "Türkiye'de Halk Ağzından Derleme Sözlüğünde Bulunup Diyarbakır Ağzında Kullanıldığı Belirtilmeyen Söz Varlığı” olmak üzere iki başlık altında incelenmiştir.

\section{IILYAS (MALKAYA) KÖYÜ}

Diyarbakır ilinin Çüngüş ilçesine bağlı İlyas köyünün eski adı Elyos'tur. Cumhuriyet'in kuruluşu ile birlikte köyün adı, köyün yakınındaki Malkaya tepesinden esinlenilerek Malkaya daha sonra ise Ilyas olarak değiştirilmiştir. Köy, Diyarbakır'ın büyükş̧ehir olmasından dolayı günümüzde Çüngüş ilçesine bağlı bir mahalle statüsündedir.

Osmanlı Kanunnamelerinde köy ile ilgili şu bilgiler yer almaktadır: "Köyün Osmanlı dönemindeki ismi Eylos'tur (bu zamanla köy dilinde Elyos olmuştur) ve civardaki 6 Türk-Müslüman köyünden biridir. Diğer köyler de sirasıyla Arguna (halk dilinde Arduva) Herahmine, Ermene, Agud (halk dilinde Avut), Karacakaya (halk dilinde Karakaya) dır" (Akgündüz, 1991: 247).

İlyas köyü, Diyarbakır'dan $122 \mathrm{~km}$, Çüngüş̧ten ise $6 \mathrm{~km}$ uzaklıktadır. Elazığ, Malatya ve Adıyaman il sınırlarına çok yakın olan köyden bu yollara açılan karayolu yoktur. Ayrıca Fırat Nehri de Adıyaman ve Malatya illerine ulaşımı engellemektedir. Elazı̆̆ iline doğrudan kara yolu bulunmayıp ulaşım toprak yollarla sağlanmaktadır. Köyün yerleşim yerinin rakımı 1200 metre civarındayken köyün yakınında bulunan Gevherbaba Tepesi'nin rakımı $2300 \mathrm{~m}$ civarıdır. Bundan dolayı kışları çok soğuk yazları ise serin ve 11 k geçer.

Dağl1k bir köy olan İlyas köyünde ekilebilir arazilerin azlığından dolayı nüfusun büyük bir kısmı büyük şehirlere göç etmiştir. Kış aylarında köyün 30-40 hane olan nüfusu yaz aylarında şehirde yaşayanların köylerine dönmesiyle 200 haneye kadar çıkmaktadır. Köyün temel geçim kaynağ tarım ve hayvancılıktır ancak köy dağl1k olduğundan ötürü köylüler ancak kendilerine yetecek kadar üretim yapmaktadırlar. 


\section{ILYAS KÖYÜNDEN (DIYYARBAKIR-ÇÜNGÜŞ) DERLEME SÖZLÜĞÜNE KATKILAR}

3.1. İlyas Köyünde Kullanılıp Türkiye'de Halk Ağzından Derleme Sözlüğünde Bulunmayan Söz Varlı̆̆1

acımublub: a. Sabırsız davranmak.

acıb etmek: İnatçılık etmek, birinin zıddına gitmek.

abırı: (< Ar.) zf. Sonunda, nihayet.

asturab: < arastak / arasdak / arıstah / arustak 'tavan' < Erm. arasdag (TETTL-I: 423) a. Tavan.

bağdanos (mağdanos $<$ Yun. makedonysi): a. Maydanoz. kullanılan yer.

başocag̀ı: a. Evlerde odanın bir köşesinde banyo yapmak için berdüş: $a$. Orta boy kazan.

bitögü: < bitemi 'Uzunluk ölçüsü birimi' < ET bi:r+täm 'birden, tamamıyla, büsbütün, toptan' (TTTSKBS-I: 151) zf. Bölünmemiş, bütün.

cenger (ol-) (Far. zeng "pas" ve ār "getiren" ile zeng-ār > jengār): $z f$. Kalaylı kapların kalayının bozulmuş hali. Zuhal Ölmez, "cengari” kelimesini “bakır pası rengi” anlamıyla Diyarbakır' dan derlemiştir (Ölmez, 2010: 194).

crrtlan: (sirt+lan < ET) a. Sirtlan.

crrtlanlıb: a. Aksilik, yaramazlık.

çangal: $a$. Şelale.

çèllaḳa: $s f$. Sulu, kendini bilmez.

çinçanagia çıbarmab: Çocukların omuz üstüne alınması.

çinemelik: a. Omuzda taşınacak kadar odun, ot vb. yük.

dikdikiye kalkmak: Ayak parmaklarının uçlarına basarak yürümek.

dil örkenmek: Birinin konuşmasını alaylı bir şekilde taklit etmek.

dingil: sf. Çıplak. DS'de "çırılçıplak" anlamında kullanılan "dasdingil" kelimesi Anadolu ağızlarından derlenmiştir (DS, II: 1374).

domun: $a$. Su taşımada kullanılan büyük teneke kap.

dövürmek ( $<$ ET tevir-mek): Devirmek. 
dügüm: $a$. Deride çıkan et parçası gibi yuvarlak ve sert şekilli siğillere verilen ad.

dünge: a. Topraktan yapılmış üstü dar, altı geniş saç ayak yerine kullanilan malzeme.

ense: $s f$. Arka taraf.

essálatı: zf. Bilerek, isteyerek, kasten. Kelime Anadolu ağızlarından esāalet (eselet) şeklinde "bilerek, isteyerek, kasten" anlamıyla derlenmiştir (DS, III: 1778).

ev çarpmah: Süpürge otundan yapılan süpürgeyi; beyaz veya kırmızı toprak, kireç ve kaya tuzundan yapılan karışımla evin duvarlarına çarparak boyamak.

ferfene: $z f$. Gençlerin ve çocukların bayram vb. günlerde bir araya gelerek yaptıkları eğlence, piknik. Ferfene kelimesi DS'de "felfele, ferfana, ferfane, felfene, ferfere" kullanımlarıyla "1. Ortaklaşa yapılan yemekli, içkili toplant1. 2. Dügün ya da bayramlarda gençlerin birleşerek bir kuzu ya da koyun kesip yemeleri. 3. Çocukların ayrı ayrı evlerden malzemelerini toplayıp kırda yaptıkları pilav. 4. Pişmiş yumurta." anlamlarıyla derlenmiştir (DS, III: 1845).

feriktirmek: Konuşmasıyla rahatsız etmek, sıkıştırmak.

gabırıb: kakrık < kāa 'yansıma'+kır-(1)k (TTTSKBS-I: 453) a. Balgam. Kelime "kakırmak" şeklinde "balgam çıkarmak" anlamında Anadolu ağızlarından derlenmiştir (DS: 2604). Kelime Hakas Türkçesinde "hağırmak" şeklinde "Öksürüp tükürmek, balgam tükürmek" (Omuralıeva 2020: 111) anlamıyla kullanılmaktadır.

gezeme: $a$. Evlerde odaların arasındaki aralık, boşluk.

gusşhana: a. (T. kuş + Far. hâne) Tencere, küçük tencere (Sağır, 1995:

bab: a. İmece usulüyle köylülerin sütlerini birleştirmeleri (bir çeşit ortaklık). DS'de "hap" kelimesi "Köylülerin yağ, peynir yapmak için sıra ile sütlerini birleştirmeleri işlemi, imece" anlamıyla derlenmiştir (DS, III: 2276).

bampek: a. Evden ahıra doğru inen merdivenlerin üzerine örtülen ağaçtan kap1.

barz etmek: Hoşlanmak. 
haybangeme: $z f$. Uluorta sesli münakaşa etmek.

heketlemek: Anlatmak, hikâye etmek.

bımça: a. Avuç, bir avuç miktarı.

hüsmek Susmak, konuşmamak.

içeri ev: Hububat vb. kış malzemelerinin konulduğu depo, kiler.

irisfay etmek: (Far. rusvā-rusvāy + T. et-) Rezil rüsva etmek. leğen.

keraġan: a. Hamur yoğurmaya yarayan topraktan yapılmış büyük

kinogiu: a. Evlerde ekmek pişirmek için ekmek sacının kurulduğu yer.

kisögü: a. İlyas köyünde "Yarım yanmış odun parçası" anlamında kullanılan kelime DS'de tespit edilememiştir. Kelime aynı anlamıla "kösegi" şeklinde Elazığ ve Yöresi Ağızlarından derlenmiştir (Gülensoy ve Buran: 1994: 235). Hasan Eren, "kösegi" kelimesinin "eğsi" kelimesiyle birleştirilebileceğini belirterek kelime ile ilgi şu bilgileri vermektedir: "Anadolu ağızlarında ucu yanmış oduna 'eğsi' veya 'eksi' adı verilir. Anadolu'da 'eğsi' ( $>$ eksi) adı yanında 'ögsü' (öksü) biçimi de kullanılır. Türkçe 'eğsi' adının kökü bugüne değin bilinmiyordu. Bizim görüşümüze göre, bu ad Türkçe köseği 'ucu yanmış odun, eğsi' adıyla birleştirilebilir. Türkçede 'köseği' adı 'ateşi karıştırmaya yarayan odun veya demir' olarak da kullanılır. Ateşi karıştıran odunun bir ucunun yanması doğaldır. $\mathrm{Bu}$ bakımdan 'köseği' adı kolaylıkla 'ucu yanmış odun' anlamını almıştır. Köseği kelimesinin Türkçe köse- 'yakmak' kökünden geldiği açıktır. kösegü > köseği” (Eren, 1978-1979: 12-13).

küllah (külâh < Far.): Başa giyilen külah (Özçelik, 1997: 264).

lag etmek: (lāg < Far.) Alay etmek, küçümsemek. (Olcay, Ercilasun ve Aslan: 1998: 389).

lembekir: a. Bakırdan yapılmış büyükçe tabak. Kelime Çüngüş ve Çermik yöresinden "lembeki" şeklinde "ağzı açı büyük bal tabağı" anlamıyla derlenmiştir (Boz, 1996: 112).

log̉durgıç: (log < Far.) a. İlyas köyünde "loğ” kelimesi "Taştan yapılmış olup evlerin üzerindeki toprağı sıkıştırmak için kullanılan silindir yapıdaki taş parçası." anlamıyla kullanılmaktadır. Kelime DS'de bu anlamıyla Anadolu ağızlarından derlenmiştir (DS, III: 3083). "Log̉durgıç" kelimesi ise İlyas köyünde "Genelde oyum ağacindan yapılan loğu çekmeye 
yarayan aparat" anlamında kullanılmakta olup DS' de yer almamaktadır.

malagof: $a$. Bayanların elbisenin altına giydiği dizlere kadar uzayan iç elbise. "Malakof, ilk defa Kırım harbinde Rusların Sivastopol müstahkem mevkiindeki Malakof Tabyası'nın Fransızlar tarafından zapt edilmesi vesilesiyle İstanbul'da Fransiz Sefarethanesinde verilen zafer balosunda giyildiği için bu ismi almıştır; halk arasında buna sepetli fistan da denirdi" (MBTS: 765).

mekirif: (kerh $<$ Ar. sf. Tiksinti veren, pis.

miğıl yemek: Hoşlanmamak.

obmaki: bağ. Belki, meğerse.

öskemek: Özlemek. Kelime "öksemek" şeklinde Anadolu ağızlarından derlenmiştir (DS: 3328).

pırbenk: $a$. Topraktan yapılmış su künkü.

piyer: $a$. Çeşme, pinar.

pöşgül: $a$. Havlu.

sadama: ed. Sadece, yalnız.

saraftaşı: a Başocağının (bk. başocağı) zeminine konulan genelde $1,5 \times 1,5 \mathrm{~m}$ boyutlarında yaklaşık $5 \mathrm{~cm}$ yüksekliğinde üçgen şeklinde yekpare taş.

segelmek: Uyuşmak, donmak.

semte gelmek: Kolayına gelmek.

soviuşmak: Savuşmak, çekip gitmek. Kelime "savuşmak" şeklinde "savuşmak, kaçmak" anlamıyla Diyarbakır'dan derlenmiştir (Erten 2011: 169).

sörke salı: $a$. Üzerinde ekmek pişirilen yassı, düz taş.

sümük: a. Toprak damların etrafının düz, yassı taşlarla dizilmesiyle yapılan saçak.

sütçöpü: a. Evler arasında imece usulüyle sütlerin birleştirilmesi anlamına gelen habcılıkta kullanılan ölçü çubuğu.

tanugiun: $a$. Un ve tarhana ile yapılan bir tür bulamaç.

tikelenmek: dikel- < ET tik+el- (TTTSKBS-I: 283) Diklenmek. 
toganmab: < tokın-mak ET Dokunmak. Kelime "dohanmak" şeklinde Keban, Baskil ve Ağın Yöresi Ağızlarından derlenmiştir (Buran, 1997: 189). birikinti.

tumtug: a. Damlardan kürelenen karın, atıldığı yerde oluşturduğu

uruncab: $a$. Hamak şeklinde yapılan salıncak.

yengicek: (<yèg+(i)n) sf. "Taşınması kolay, hafif. Kelime "yenlicek" şeklinde Anadolu ağızlarından derlenmiştir (DS, VI: 4822).

zımzıb: a. Yumruk. Kelime "zımzık" şeklinde Anadolu ağızlarından derlenmiştir (DS, VI: 4372).

zonga: a. Kapının iç tarafına bir delik açılarak kapının arkadan kilitlenmesine yarayan tahtadan yapılan sürgü.

3.2. Türkiye'de Halk Ağzından Derleme Sözlüğünde Bulunup Diyarbakır Ağzında Kullanıldığı Belirtilmeyen Söz Varlığı

bıbçı a. Testere. (DS, I: 657) < bıçkı 'testere; saraç bıçağı, bağ bıçağı' < ETk. bıçg.u [bıç- 'kesmek' +fiilden alet ismi yapan -g1/k1 eki] (TETTL-I: 685).

bıldır: $z f$. Geçen sene (DS, VI: 4459). < bıldır 'geçen sene, bir yıl önce' < bir yıldır (TETTL-I: 687).

cızma: a. Çizme. Kelime "Konçlu ayakkabı, çizme" anlamıyla Anadolu ağızlarından derlenmiştir (DS, II: 992).

çaġa: a. Çocuk. (DS, II: 1033) < çāka. Trkm. çāgaa, Az. çağa "çocuk, yavru süt çocuğu' TatT. bala-çağa, 'büyük küçük çocuklar” Özb. bala-çaka, Uyg. bala-çaka. 'çoluk çocuk' Moğ. çaka (TTTSKBS-I: 210).

çin: a. Omuz. (DS, II: 1225; Buran, 1997: 187; Erten, 2011: 152). Kelime Uşak İli Ağızlarında uzun ünlülü olarak tespit edilmiştir. (Gülsevin, 2002: 373). < OT çik 'dik+(i)n; Çağ., EAT. çigin (TTTSKBS-I: 241).

gocik: a. (Bulg. kojux) Kalın kumaştan yapılan ve içine deri astar geçirilen kısa palto (DS, III: 2089).

gubaşmab: İmece ile iş görmek, yardımlaşmak (DS, V: 3745).

heket: a. Hikâye (DS, III: 2330).

hers: Öfke (DS, III: 2347).

köpüç: (< köpür-(ü)ç) a. İlyas köyünde "Çamaşırları yıkamak ve 
damların topraklarını sıkıştırmak için kullanılan tahtadan yapılmış alet." anlamıyla kullanılan kelime DS'de "Çamaşır tokacı" anlamıyla derlenmiştir (DS, III: 2962).

log̀: a. (< Far.) Taştan yapılmış olup evlerin üzerindeki toprăg 1 sıkıştırmak için kullanılan silindir şeklindeki taş (DS, III: 3083).

lülük: a. İbriğin emziği (DS, III: 3095). < lülük / lüllük / lolik 'çaydanlığın ağzı, su akan küçük boru' <lüle+-ik küçültme eki (TETTL-4 $560)$.

malamat etmek: (< levm Ar.) Birinin ayıbını açığa çıkarmak, rezil etmek (DS, IV: 3112).

migahat olmak: İlyas köyünde "Mukayyet olmak, sahip çıkmak." anlamında kullanılan kelime "mıhağat" ş̧eklinde "iye, sahip" anlamıyla Anadolu ağızlarından derlenmiştir (DS, IV: 4596).

mucurum: $s f$. Kötürüm, yatalak, topal (DS, IV: 3216).

ötme: a. Evin ön duvarı üstüne gelen dam uzantısı, ön saçak (DS, V: 3352). 3506).

püşürük: $a$. Toprak damlı evlerde dama döşenen cıvık çamur (DS, V:

sal: (< ET sal: düz, yassı taş; sal daş: düzgün büyükçe taş) a. İlyas köyünde "İnce, geniş taş parçası." anlamında kullanılan kelime "Kaldırım yapmakta kullanılan yassı ve büyük taş" anlamıyla derlenmiştir (DS, V: 3522).

sálabana: $s f$. Serseri, başıboş (DS, VI: 4666).

seplemek: Birakmak (DS, VI: 3587).

sırtarmab: Dişleri görünecek şekilde gülmek (DS, VI: 3621).

sürgü: a. Kar küreği (DS, VI: 4715).

şabalamab: (< şaḳk Ar.) Parçalara ayırmak, bölmek (DS, VI: 3737).

şapalab: a. Tokat (DS, V: 3746).

tay: a. Eş, denk, yaşı1t (DS, V: 3852).

terek: a. Raf, sergen (DS, V: 3891). < Çağ., AH.: täräk <tér'dermek' +-ek (DLT: térgelir 'dermek, toplamak üzere olan') (TTTSKBS-I: 884). 
tıbım: (tikü < tikkü ET) a. Parça, lokma, dilim (genellikle et, ekmek, peynir vb. için) (DS, V: 3931).

töremek: (< törü- ET) Çoğalmak, üremek (DS, VI: 4775).

üsküre: a. (Far. uskere) Büyükçe bakır kâse (DS: 4798).

zırza: a. Genellikle ceviz, gürgen ve dişbudak ağacından yapılan, bıçkıya benzer mekanik yapılı kapı anahtarı (DS, VI: 4382).

\section{SONUÇ}

Diyarbakır ili Çüngüş ilçesine bağlı İlyas (Malkaya) köyünden söz varlığının derlendiği bu çalışmada 100 kelime incelenmiştir. $\mathrm{Bu} 100$ kelimenin 70'i Türkiye'de Halk Ağzından Derleme Sözlüğünde bulunmayan kelimeler olup 30 tanesi Türkiye'de Halk Ağzından Derleme Sözlüğünde bulunup Diyarbakır ağzında kullanıldığ 1 belirtilmeyen kelimelerden oluşmaktadır.

Derlenen Arapça, Farsça vb. kökenli kelimelerin bazılarının artlık önlük uyumu açısından Türkçeye uydurulduğu görülmektedir. [bk. cenger (zengâr), mekirif (mekruh)] Arapça, Farsça kökenli kelimelerin bazılarından Türkçe eklerle yeni kelimelerin türetildiği görülmektedir (bk. log̉durgıç, heketlemek). Eski Türkçede kullanılan çağa, bıldır, sal gibi kelimelerin İlyas köyü ağzındaki varlığı Türkçenin eskicil (arkaik) izlerini gösteren önemli ipuçlarıdır.

Teknolojinin hızlı bir şekilde geliştiği ve ağız özellikleri gösteren söz varlığının hızla yok olduğu günümüzde ağızlardaki söz varlığının yazıya geçirilmesi Türk dilinin gelişim sürecinin izlenmesi açısından ağız araştırmalarına katkı sağlayacaktır. Söz varlığının tespit edildiği bu tür çalışmalar sayesinde karşılaştırmalı ağız çalışmalarını daha sağlıklı bir şekilde yapmak mümkündür.

\section{Teşekkür}

Ahmet Çiftçi (Yaş 68)

Fatma Çiftçi (Yaş 62)

Mustafa Uğurlu Arslan (Yaş 41)

Salime Arslan (Yaş 74)

Saniye Başdemir (Yaş 89)

Yasin Başdemir (Yaş 44)

\section{Kisaltmalar}

a. $\mathrm{ad}$ 


$\begin{array}{ll}\text { Ar. } & \text { Arapça } \\ \text { bağ. } & \text { bağlaç } \\ \text { Bulg. } & \text { Bulgarca } \\ \text { Çağ. } & \text { Çağatay Türkçesi } \\ \text { DLT } & \text { Dîvân-1 Lügâti’t-Türk } \\ \text { DS: } & \text { Derleme Sözlüğü } \\ \text { DS, I } & \text { Derleme Sözlügü Birinci Cilt } \\ \text { DS, II } & \text { Derleme Sözlüğü İkinci Cilt } \\ \text { DS, III } & \text { Derleme Sözlüğ̈ü Üçüncü Cilt } \\ \text { DS, IV } & \text { Derleme Sözlüğü Dördüncü Cilt } \\ \text { DS, V } & \text { Derleme Sözlüğü Beşinci Cilt } \\ \text { DS, VI } & \text { Derleme Sözlüğü Altınci Cilt } \\ \text { EAT } & \text { Eski Anadolu Türkçesi } \\ \text { ed. } & \text { edat } \\ \text { ET } & \text { Eski Türkçe } \\ \text { Far. } & \text { Farsça } \\ \text { Moğ. } & \text { Moğolca } \\ \text { OT } & \text { Orta Türkçe } \\ \text { Özb. } & \text { Özbek Türkçesi } \\ \text { T. } & \text { Türkçe } \\ \text { TatT. } & \text { Tatar Türkçesi } \\ \text { TETTL } & \text { Tarihi ve Etimolojik Türkiye Türkçesi Lügati } \\ \text { Trkm. } & \text { Türkmen Türkçesi } \\ \text { TS } & \text { Türkçe Sözlük } \\ \text { TTTSKBS } & \text { Türkiye Türkçesindeki Türkçe Sözcüklerin Köken } \\ & \text { Bilgisi Sözlüğü } \\ \text { zf. } & \text { zarf }\end{array}$

\section{Çeviri Yazı İşaretleri}

$\begin{array}{ll}\text { á } & \text { a-e arası ünlü } \\ \bar{a} & \text { uzun a } \\ \text { ä } & \text { açı e } \\ \dot{e} & \text { e-i arası ses } \\ \overline{\mathrm{i}} & \text { uzun i sesi } \\ \mathrm{h} & \text { arka damak h ünsüzü } \\ \mathrm{k} & \text { arka damak k ünsüzü } \\ \dot{\mathrm{v}} & \text { çift dudak v ünsüzü } \\ \cdot & \text { ayın }\end{array}$




\section{KAYNAKLAR}

Akgündüz, A. (1991). Osmanlı kanunnâmeleri ve hukukî tahlilleri: Yavuz Sultan Selim Devri kanunnâmeleri III. İstanbul: Fey Vakfi Yayınları.

Ayverdi, İ. (2010). Misalli Büyük Türkçe Sözlük. İstanbul: Kubbealtı Yayınları.

Baran, B. \& Erten, M. (2020). Diyarbakır ağzında sözcük yitimi. B. Tunçsiper ve D. İnan (Ed). İzmir Demokrasi Üniversitesi Uluslararası Beşerî Bilimler Kongresi bildiriler kitabı içinde (ss.378-383). İzmir: İzmir Demokrasi Üniversitesi.

Baran, B. (2019). Güneydoğu Anadolu ağızlarının dil özellikleri üzerine bir inceleme. H. Eriş ve M. Kıdıryüz (Ed.).1.Uluslararası Harran Multidisipliner Çalışmalar Kongresi bildiri kitabı içinde (ss. 1413-1436). İksad Yayınları

Baran, B. (2020). Diyarbakır ili ağızlarında şimdiki zaman ekleri ve kullanılışları. Mecmua-Uluslararası Sosyal Bilimler Dergisi, 5(10), 17-32.

Başkan, A. \& Erten, M. (2016). Bismil ağzından derleme sözlüğüne katkılar. Cumhuriyet Üniversitesi Edebiyat Fakültesi Sosyal Bilimler Dergisi, 40(2), 67-77.

Başkan, A. (2012). Bismil ağzı, inceleme-metinler-dizin. Yayımlanmamış Yüksek Lisans Tezi. Dicle Üniversitesi, Diyarbakır.

Başkan, A. \& Özkan, E. (2017). Bismil (Diyarbakır) ağzında arkaik sözler. Journal of Social And Humanities Sciences Research, 4 (11), 537-540.

Beysanoğlu, Ş. (1966). Diyarbakır ağzı. Ankara: Diyarbakır Halkevi Yayınları.

Boz, E. (1996). Çüngüş ve Çermik yöresi ağzından derleme sözlüğüne katkılar. Milli Folklor, 4, 112-113.

Buran A. (1997). Keban, Baskil ve Ağgn yöresi ăğzları. Ankara: Türk Dil Kurumu Yayinları.

Eker, S. (2008). Türk Dili tarihinde bir dilbilimsel temas bölgesi olarak Diyarbakır. B. Yediylddz ve K. Tomenendal (Ed.). Osmanlıdan Cumhuriyete 2. Uluslararası Diyarbakır Sempozyumu bildiriler kitabı içinde (ss. 91-110). Ankara: Türk Kültürünü Araştırma Enstitüsü.

Eren, H. (1978-1979). Türk dilinin etymologıque sözlüğüne katkılar. Türk Dili Araştırmaları Yillı̆̆ Belleten, 1-15.

Erten, M. (2011). Diyarbakır ağzı. Ankara: Türk Dil Kurumu Yayınları.

Gülensoy T. \& Buran A. (1994). Elazı̆̆ yöresi ă̆ızlarından derlemeler. Ankara: Türk Dil Kurumu Yayınları.

Gülensoy, T. (2011). Türkiye Türkçesindeki Türkçe sözcüklerin köken bilgisi sözlüğ̈̈. Ankara: Türk Dil Kurumu Yayınları.

Karahan, L. (2011). Anadolu ăğzlarının sınıflandırılması. Ankara: Türk Dil Kurumu Yayınları.

Nakiboğlu S. H. (2015). Diyarbakır, Mardin, Urfa-Siverek ağızlarında kullanılan bir enklitik edatı "MA". Akademik Bakış Dergisi, 47, 272-286.

Olcay, S., Ercilasun, Ahmet B. \& Aslan, E. (1997). Arpaçay Köylerinden Derlemeler. Ankara: Türk Dil Kurumu Yayınları.

Omuralieva, A. (2020). Türkçede ses yansımalı fiiller türeten +kır- eki üzerine. 
Folklor Akademi Dergisi, 3(1), 99-130.

Ölmez, Z. (2010). Diyarbakır ağzının sözvarlığına katkılar. Türk Dilleri Araştırmaları, 20. 193-201.

Özçelik S. \& Boz E. (2001). Diyarbakır ili Çüngüş ve Çermik yöresi ağzı (dil incelemesi, metinler, sözlük). Ankara: Türk Dil Kurumu Yayınları.

Özçelik S. (1997). Urfa merkez ăgzı, inceleme-metinler-sözlük. Ankara: Türk Dil Kurumu Yayınları.

Sağır M. (1995). Erzincan ve yöresi ă̆ızları, inceleme-metinler-sözlük. Ankara: Türk Dil Kurumu.

Sökmen, İ. (2016). Bismil Türkmen A ğzı. Ankara: Türk Dil Kurumu Yayınları.

Sökmen, İ. (2017). Dilsel veriler ışığında Bismil Türkmen topluluğu ve ağzını oluşturan tarihsel katmanlar. Türk Dünyası, Dil ve Edebiyat Dergisi, 44, 215-235.

Tietze, A. (2009-2018). Tarihi ve etimolojik Türkiye Türkçesi Lügatı. 1-5 Cilt. İstanbul.

Türkiye'de Halk ă̆zından derleme sözlüğü I-VI. Cilt (2009). Ankara: Türk Dil Kurumu Yayınları.

https://web.archive.org/web/20201002021433/http://www.malkayakoyu.org/koytari hi.htm 